\title{
Effect of Bisphosphonates on Root Growth and on Chlorophyll Formation in Arabidopsis thaliana Seedlings
}

\author{
Ana I. Manzano시 F. Javier Medina ${ }^{1}$, Francisco J. Pérez-Zuñiga ${ }^{2}$, \\ Maria A. Günther Sillero ${ }^{2}$ and Antonio Sillero ${ }^{2}$ \\ ${ }^{1}$ Centro de Investigaciones Biológicas, CSIC, Madrid \\ ${ }^{2}$ Departamento de Bioquímica, Instituto de Investigaciones \\ Biomédicas Alberto Sols, UAM/CSIC, Facultad de Medicina, Madrid \\ Spain
}

\section{Introduction}

Bisphosphonates (BPs) are analogues of pyrophosphate in which the oxygen bridge between the two phosphates is replaced by a methylene group $\left(-\mathrm{CH}_{2}-\right)$. Substitution of one or both hydrogen atoms of this group by radicals generates a variety of bisphosphonates; usually they are grouped into two types, namely non-N-BP and N-BP, depending on the absence or presence of a nitrogen atom in its molecule, respectively (Russell, 2011). Examples of BPs used in this report are: etidronate and clodronate (non-N-BPs), and pamidronate and alendronate (N-BPs).

Bisphosphonates are the leading drug class for the treatment of osteoporosis; as an indication of their usefulness and the spread out of the disease the combined sales of drugs to treat osteoporosis reached $\$ 6.2$ billions in 2004. Besides their application in humans, bisphosphonates are also used for other purposes, mainly as herbicides in plants (Cromartie et al., 1999; Oberhauser et al., 1998), as chemotherapeutic agents (Artz et al., 2008; Docampo \& Moreno, 2001; Leon et al., 2006; Moreno \& Li, 2008) and in basic research (Rogers et al., 2010; Russell, 2011).

The usefulness of bisphosphonates is due to their mechanism of action when they are supplied to the living organism. In fact, they have the ability of interfering with metabolic pathways located at the crossroads of essential processes for life. Some important examples of this crucial role are as follows:

a) Bisphosphonates may act as analogs of PP in many of the reactions catalyzed by ligases

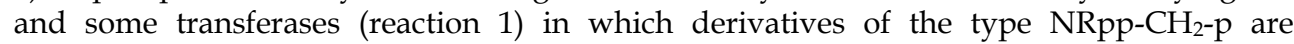
synthesized in the reverse reaction (reaction 2) (Günther Sillero et al., 2008; Günther Sillero et al., 2006; Rogers et al., 1996; Russell, 2011).

$$
\begin{gathered}
\mathrm{X}+\mathrm{NRPPP}---->\mathrm{X}-\mathrm{NRP}+\mathrm{PP} \\
\mathrm{X}-\mathrm{NRP}+\mathrm{p}-\mathrm{CH}_{2}-\mathrm{p}--->\mathrm{NRpp}-\mathrm{CH}_{2}-\mathrm{p} \\
\mathrm{X}-\mathrm{NRP}+\text { mev-pp --->mevpppN }
\end{gathered}
$$


Where $X$ is a potential substrate of the reaction; NRP and NRPPP are nucleosides mono- and triphosphates, respectively; NRpp- $\mathrm{CH}_{2}$-p is a nucleoside $5^{\prime}(\beta, \gamma$ methylene triphosphate) and mev-pp a compound of the mevalonate pathway with a terminal pyrophosphate (see below). As the more abundant nucleoside triphosphate is ATP, the more common derivative from bisphosphonate, would be ARpp- $\mathrm{CH}_{2}$-p; given that ATP is a co-substrate of at least 150 enzymes with transferase activity and more than 90 with ligase activity (see Enzyme Nomenclature), bisphosphonates may indirectly interfere with multiple cellular processes through the formation of bisphosphonate derivatives of ATP or of any nucleoside triphosphate. As in these reactions BPs act as analogs of PP it would be expected that the non-N-BP (the smallest type of $\mathrm{BP}$ ) were the preferred substrates for these reactions.

b) BPs may be inhibitors of enzymes having substrates with a terminal PP (R-PP) (see below and Günther Sillero et al., 2009). Although the inhibition of these enzymes could take place at any step of the pathway, specific inhibitions have been reported on isolated enzymes from bacteria, yeast or plants: pyrophosphatase (Baykov et al., 1993; Cromartie et al., 1999; Drozdowicz et al., 2003; Gordon-Weeks et al., 1999; Kim et al.,1994; Kuo et al., 2005; Rodrígues et al., 2000; Szabo \& Oldfield, 2001; Zhen et al., 1994 ); geranyl diphospho synthetase (Burke et al., 2004; Oberhauser et al., 1998); isopentenyl pyrophosphate synthase (Cromartie et al., 1999) and P5C reductase (Forlani et al., 2008).

c) The synthesis of isopentenyl triphosphoadenosine (iso-pppA) was previously described (Monkkonen et al., 2006). Following this finding, the synthesis of derivatives of a variety of compounds of the mevalonate pathway capped with an adenosine moiety catalyzed by several ligases, was later reported (mev-pppA and mev-ppppA) (Günther Sillero et al., 2009). Increase in the concentration of metabolites upstream the inhibited step could stimulate synthesis of the corresponding mevalonate derivative (reaction 3) (Günther Sillero et al., 2009; Rogers et al., 2010).

Related to the use of bisphosphonates in humans for the treatment of osteoporosis, Paget's disease and bone tumour metastasis it can be stressed that upon their oral or intravenous administration BP are partially eliminated by kidney and partially fixed in bones, with very little amount in the systemic circulation (Cremers et al., 2005). Being otherwise bisphosphonates could have general toxic effects. After their capture by osteoclasts from the bone they exert noxious effects on these cells by some of the above-mentioned mechanisms. The basic approach, necessary to explore the effect of BPs, is not sufficient to envisage their clinical effects. These studies, although mandatory, are cumbersome, costly and requiring a cohort of patients as each patient has distinct characteristics and each bisphosphonate may present special pharmacokinetic properties (Cremers et al., 2005).

Based on the above we thought of interest to approach the effect of bisphosphonates in plants: plants are a whole living entity, of cheaper handling, where BPs present a quite different pharmacokinetics; they are easily assimilated by the roots, are not fixed in a structure similar to bones and probably circulate through the vegetal tissues more easily than in animal tissues. As an initial approach to the problem, we have used germinating seeds and early seedlings of the model plant species Arabidopsis thaliana to investigate the alteration of a few phenotypic characters, considered of high relevance for key functions of the plant, namely the seed germination rate, the early development of primary and secondary roots (essential for establishing the plant developmental pattern) and the presence and content of chlorophyll in the first leaves. This later character, used as an indicator of the ability of plants for performing the fundamental process of photosynthesis, also indicates the alteration of the mevalonate pathway, since chlorophyll is a product of 
this biosynthetic pathway. We have focused our attention on this pathway as a good target to examine the effect of $\mathrm{BP}$ given the two metabolic peculiarities present only in the mevalonate cycle: occurrence of both three consecutive enzymes requiring ATP as a cosubstrate and the major pool of compounds containing a terminal pyrophosphate in any known metabolic pathway (Günther Sillero et al., 2009) (Fig. 1).

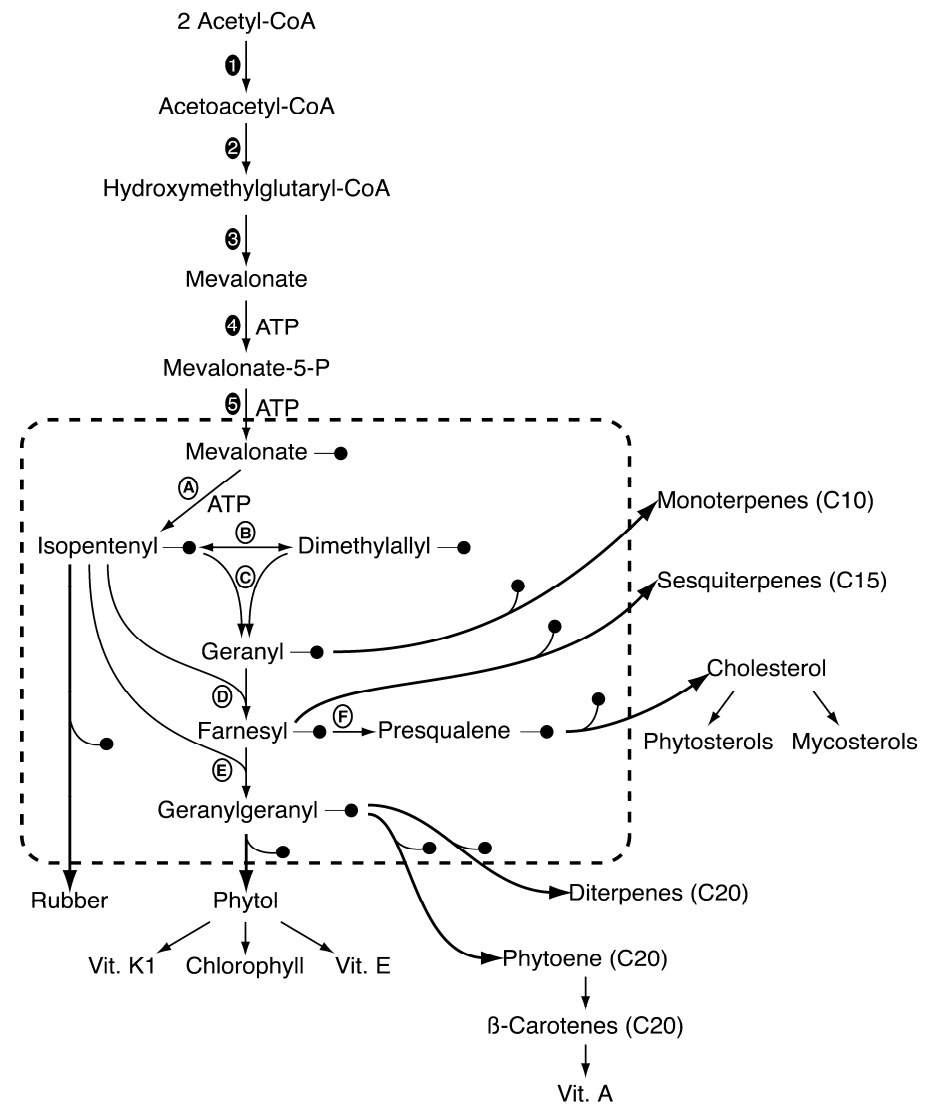

The metabolic pathway from acetyl-CoA to mevalonate-5-phospahte, and the implicated enzymes (1-5) are indicated in the figure. The enzymes are: 1, acetyl-CoA acetyltransferase (EC 2.3.1.9); 2,

hydroxymethylglutaryl-CoA synthase (EC 4.1.3.5);3, 3-hydromethylglutaryl-CoA reductase, (EC 1.1.1.34); 4, mevalonate kinase (EC 2.7.1.36); 5, phosphomevalonate kinase (EC 2.7.4.2). Note that the three consecutive steps catalyzed by enzymes (4), (5) and (A), consume three moles of ATP. The inset in the figure comprises the compounds of the mevalonate pathway and the enzymes (A-F) involved: A, diphosphomevalonate decarboxylase, (EC 4.1.1.33); B, isopentenyl-diphosphate D-isomerase, (EC 5.3.3.2); C,

dimethylallyltranstransferase, (EC 2.5.1.1); D, geranyltranstransferase (farnesyl-diphosphate synthase), (EC 2.5.1.10); E, farnesyltranstransferase, (EC 2.5.1.29); F, farnesyl-diphosphate farnesyltransferase, (EC 2.5.1.21). To emphasize the occurrence of pyrophosphate in all the compounds of the cycle, this moiety has been marked out $(\bullet)$. Some of the great variety of compounds synthesized from those metabolites, and essential for plant functions, is annotated. The mevalonate independent pathway is not represented in the Figure.

Fig. 1. Components of the mevalonate pathway, its precursors and some metabolic connections in plants. 
The cytosol-located mevalonate pathway (starting with 2 moles of acetyl-CoA and ending in geranygeranyl pyrophosphate (Fig. 1)) is the starting point for the synthesis of a great variety of compounds in bacteria, plants and animals, embracing more than 23,000 currently identified compounds (Wendt \& Schulz, 1998). A different additional route for the synthesis of isopentenyl pyrophosphate is localized in plant plastids. This mevalonate-independent pathway starts with the condensation of pyruvate and D-glyceraldehyde 3-phosphate and, through the action of seven additional enzyme activities, the synthesis of isopentenyl pyrophosphate is obtained (see (Hunter, 2007) for a review).

This short work is an initial report of this study, showing that the plant growth and development, as well as the photosynthetic efficiency, are indeed affected by the presence of BPs in the culture medium, in some cases in such an extent that the actual viability of the plant is compromised. Apart from its basic interest, this finding could be of some help to understand the role of bisphosphonates in animal tissues.

\section{Materials and methods}

The following bisphosphonates were used in this study: alendronate, $\mathrm{pC}(\mathrm{OH})\left(\left(\mathrm{CH}_{2}\right)_{3}-\mathrm{NH}_{2}\right) \mathrm{p}$ (Ref. A-4978) and etidronate, $\mathrm{pC}(\mathrm{OH})\left(\mathrm{CH}_{3}\right) \mathrm{p}$ (Ref. P-5248) were from Sigma; clodronate, $\mathrm{pCCl}_{2} \mathrm{p}$ (Ref. 233183), and pamidronate, $\mathrm{pC}(\mathrm{OH})\left(\left(\mathrm{CH}_{2}\right)_{2}-\mathrm{NH}_{2}\right) \mathrm{p}$, (Ref. 506600) were from Calbiochem. In addition, sodium pyrophosphate and tripolyphosphate $\left(\mathrm{P}_{3}\right)$, used in controls, were from Sigma (Refs P9146 and T-5633, respectively).

Seeds of Arabidopsis thaliana ecotype Columbia were placed in Petri dishes containing Murashige and Skoog's (MS) medium (Duchefa) in agar supplemented with one of the four bisphosphonates (BPs) indicated, at a concentration of $0.05 \mathrm{mM}, 0.1 \mathrm{mM}$ or $0.5 \mathrm{mM}$. Controls consisted of culture medium alone, or supplemented with pyrophosphate $(0.1 \mathrm{mM}$ or 0.5 $\mathrm{mM})$, or tripolyphosphate $(0.1 \mathrm{mM}$ or $0.5 \mathrm{mM})$. Plates were placed vertically and incubated at $22^{\circ} \mathrm{C}$ under illumination with a flux of photo synthetically active photons of $150-\mu \mathrm{E} \mathrm{m}^{-2} \mathrm{~s}^{-1}$, with a photoperiod of 16 hours of light and 8 hours of darkness. Samples were photographed at 4, 8 and 11 days of incubation and analyzed for the following parameters: a) rate of germination; b) length of the primary root; c) time of appearance, number and length of secondary roots; and d) colour of leaves.

\section{Results and discussion}

The plants were analyzed by the rate of seed germination and, in germinated seedlings, by the occurrence and aspect of three visible phenotypic characters: growth (length) of the primary root, development of secondary roots (time of appearance, position, number and length) and colour of the leaves, indicative of the presence of chlorophyll. The full set of results obtained for every evaluated parameter with the four BPs, at the three concentrations and in the three time points of sampling assayed, is shown in Table 1.

In order to facilitate the presentation of the results, the experimental conditions have been numbered from 1-12 (\#column at the right in Table 1). Furthermore, representative results corresponding to $A$. thaliana seedlings grown during 4, 8 and 11 days in the presence of 0.1 $\mathrm{mM}$ etidronate; $0.05 \mathrm{mM}$ clodronate; $0.5 \mathrm{mM}$ pamidronate and $0.5 \mathrm{mM}$ alendronate are shown in Fig. 2. Controls grown without any addition to the culture medium (a-c), or in the absence of BPs, but in the presence of pyrophosphate (d-f) or tripolyphosphate (g-i), were also included in Fig. 2. 


\begin{tabular}{|c|c|c|c|c|c|c|c|c|c|c|}
\hline \multirow[b]{2}{*}{$\begin{array}{l}\text { NAME OF } \\
\text { BISPHOSPHONATE } \\
\quad \text { Parameter evaluated }\end{array}$} & \multicolumn{10}{|c|}{ Treatment } \\
\hline & 4 days & $.05 \mathrm{mM}$ & 11 days & 4 days & $\begin{array}{l}0.1 \mathrm{mM} \\
8 \text { days }\end{array}$ & 11 days & 4 days & $\begin{array}{l}0.5 \mathrm{mM} \\
8 \text { days }\end{array}$ & 11 days & $\#$ \\
\hline $\begin{array}{r}\text { ETIDRONATE (non-N-BP): } \\
\text { Primary Root Length } \\
\text { (Shortening) }\end{array}$ & + & ++ & +++ & - & - & - & + & + & ++ & 1 \\
\hline $\begin{array}{r}\text { Secondary Roots: } \\
\text { Reduction in Number and } \\
\text { Length }\end{array}$ & na & na & +++ & na & na & +++ & na & na & ++ & 2 \\
\hline Chlorophyll Loss & - & - & - & - & - & - & - & - & - & 3 \\
\hline $\begin{array}{r}\text { CLODRONATE (non-N-BP): } \\
\text { Primary Root Length } \\
\text { (Shortening) }\end{array}$ & ++ & +++ & +++ & + & ++ & +++ & + & ++ & +++ & 4 \\
\hline $\begin{array}{r}\text { Secondary Roots: } \\
\text { Reduction in Number and } \\
\text { Length }\end{array}$ & na & na & +++ & na & na & +++ & na & na & ++ & 5 \\
\hline Chlorophyll Loss & - & - & - & - & - & - & - & + & + & 6 \\
\hline $\begin{array}{r}\text { PAMIDRONATE (N-BP): } \\
\text { Primary Root Length } \\
\text { (Shortening) }\end{array}$ & - & + & ++ & - & + & ++ & ++ & +++ & +++ & 7 \\
\hline $\begin{array}{r}\text { Secondary Roots: } \\
\text { Reduction in Number and } \\
\text { Length }\end{array}$ & na & na & + & na & na & + & na & na & +++ & 8 \\
\hline Chlorophyll Loss & - & - & - & - & - & - & + & ++ & +++ & 9 \\
\hline $\begin{array}{r}\text { ALENDRONATE (N-BP): } \\
\text { Primary Root Length } \\
\text { (Shortening) }\end{array}$ & - & + & ++ & + & ++ & ++ & ++ & +++ & +++ & 10 \\
\hline $\begin{array}{r}\text { Secondary Roots: } \\
\text { Reduction in Number and } \\
\text { Length }\end{array}$ & na & na & - & na & na & +++ & na & na & +++ & 11 \\
\hline Chlorophyll Loss & - & - & - & - & + & + & - & +++ & +++ & 12 \\
\hline
\end{tabular}

The expressed results are referred to the control experiment performed with standard culture medium, without the addition of any other substance. Number of (+) indicates deviation with respect to the control experiment for the particular parameter evaluated. (-): Similar to the control experiment. na: Not applicable, because secondary roots were not initiated in the corresponding control samples. \#: Reference number of the experiment, attributed for the sake of clarity in the description and discussion of results.

Table 1. Summary of results obtained on Arabidopsis thaliana seedlings with the four bisphosphonates analyzed, the three parameters evaluated and the nine conditions used, resulting from the combination of three concentrations and three times of incubation for each bisphosphonate. 
In this initial approach, the estimation of the effects of BPs on the characters investigated has been performed in a semi-quantitative way, by recording the differences that can be appreciated in these parameters by a simple visual inspection. The purpose of this type of analysis was, firstly, to determine whether or not BPs are potent inhibitors of essential functions of the plant; secondly, to discriminate differential effects between the analyzed BPs, the concentrations used and the times of development, in order to select targets for a more detailed and deep mechanistic analysis that may provide relevant information on the specific biochemical reactions that become affected during the inhibitory process.

From the full set of data presented in Table 1, and the selected images shown in Fig. 2, the most relevant results of our study are as follows:

a) None of the tested BPs, at any of the concentrations assayed, affected the seed germination rate. b) Clodronate, pamidronate and alendronate affected both the growth of the primary root, resulting in its shortening, and the number and length of secondary roots (Table 1 and Fig. 2, m-o; p-r; s-u). c) Two BPs, belonging to the same group of non-N-BP (etidronate and clodronate) showed effects of quite different intensity on root development, and might have a different degree of action (Fig. 2, j-1; m-o) (Table 1, compare 1-3 and 4-6). d) The effect of BPs is time dependent, and the highest effect was obtained after 11 days in culture, irrespective of the concentration used. In few cases we observed that the maximum effect was already reached after 8 days and then it persisted after longer time in culture (Fig. 2, n-o; t-u) (Table 1, line 4, $0.05 \mathrm{mM}$; line 7, $0.5 \mathrm{mM}$; line 10, $0.5 \mathrm{mM}$ ). e) The effect of BPs regarding the alteration of primary root growth was concentration dependent. This feature was more clearly observed with N-BPs rather than with non-N-BPs. However, in the particular case of etidronate, concentrations of $0.05 \mathrm{mM}$ seemed to be more effective than 0.1 $\mathrm{mM}$ (Table 1, line 1), a striking result of difficult interpretation. f) There are visible differences on the influence of BPs on chlorophyll loss: non-N-BPs either did not affect visibly that parameter, even at $0.5 \mathrm{mM}$ and during 11 days in culture (etidronate; Table 1 , line 3), or affected only slightly at the highest concentration (clodronate; Table 1, line 6); on the contrary, N-BPs, such as alendronate (Table 1, line 12) and to a lesser extent pamidronate, greatly affected the colour of the leaves (Table 1, line 9) (Fig. 2, p-r; s-u). In general, conspicuous effect on chlorophyll loss was only detected at the highest BP concentrations. g) Alendronate was the most effective BP acting on Arabidopsis thaliana development, affecting the primary and secondary roots and chlorophyll loss, producing a drastic inhibition of seedling growth, with total loss of chlorophyll, which was observed at a concentration of $0.5 \mathrm{mM}$, already in the intermediate time point of sampling (Fig. 2, $\mathrm{t}-\mathrm{u}$ ) (Table 1, lines 10, 11 and 12).

Images from a to i correspond to controls, either with the standard MS culture medium alone (a to $c$ ), or with the addition of pyrophosphate ( $d$ to $f$ ), or with the addition of tripolyphosphate ( $g$ to $i$ ): the analysis of the features of these control samples (a to $i)$ does not reveal significant differences among them. From $\mathrm{j}$ to $\mathrm{l}$ : culture in the presence of $0.1 \mathrm{mM}$ etidronate for 4, 8 and 11 days, respectively; images $j$ and $k$ are practically unaltered with respect to controls; root length similar to controls, but secondary roots are much less developed (l). From $\mathrm{m}$ to o: culture in the presence of $0.05 \mathrm{mM}$ clodronate for 4,8 and 11 days, respectively; at the $4^{\text {th }}$ day of growth, primary roots are shorter $(\mathrm{m})$ than the controls (a, d and g) and the root growth appears practically arrested in successive samples ( $\mathrm{n}$ to o); secondary roots are totally absent (o). From $\mathrm{p}$ to $\mathrm{r}$ : culture in the presence of $0.5 \mathrm{mM}$ 


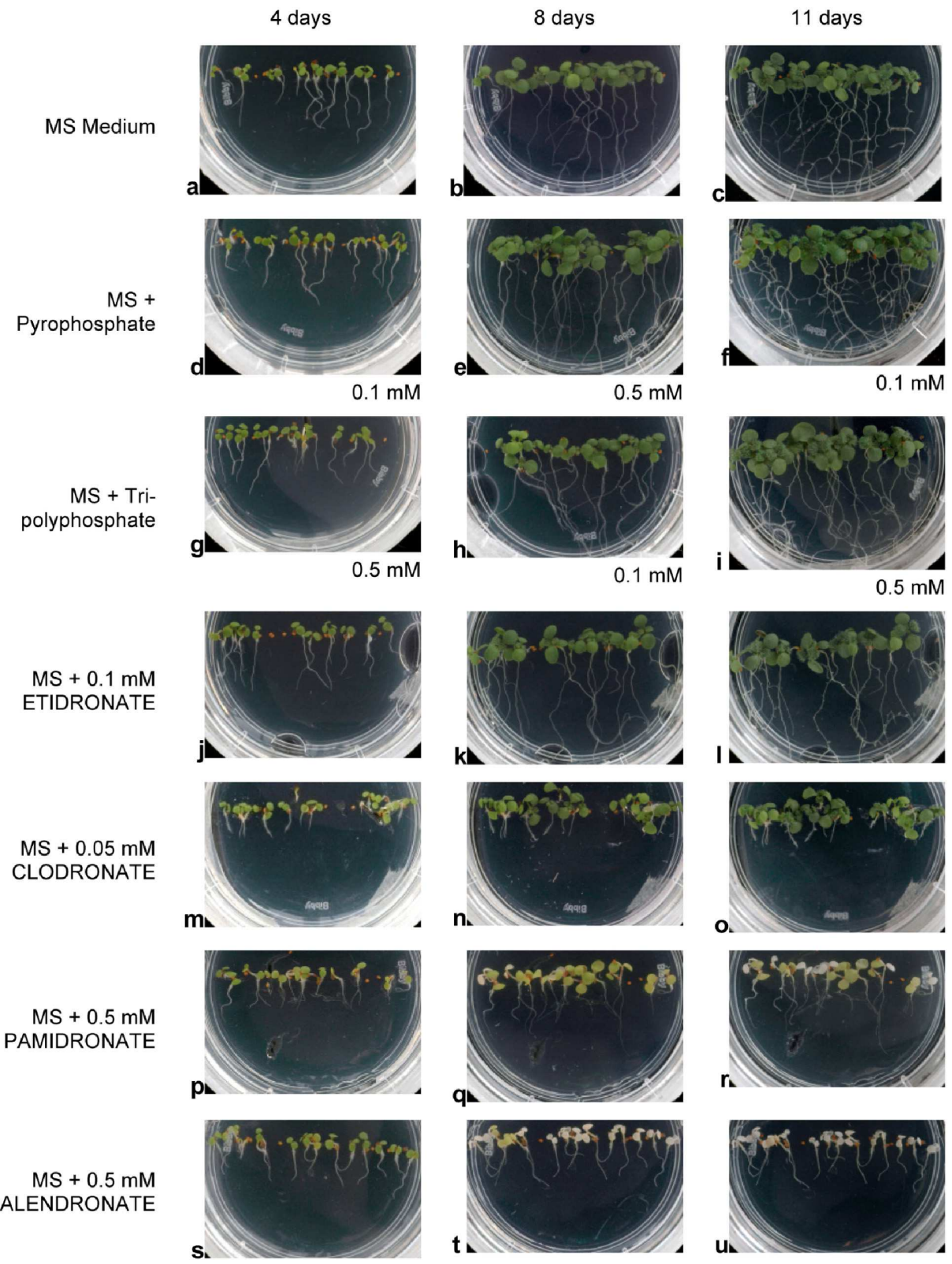

Fig. 2. Selected images of the results obtained after the germination and growth of Arabidopsis thaliana seedlings in the presence of four different bisphosphonates.

pamidronate for 4, 8 and 11 days, respectively; at the $4^{\text {th }}$ day of growth, primary roots are shorter $(\mathrm{p})$ than the controls $(\mathrm{a}, \mathrm{d}, \mathrm{g})$; the root growth does not progress further ( $\mathrm{q}$ to $\mathrm{r}$ ); leaves show a pale yellowish colour in all cases, but this effect is more intense as the culture 
in the presence of the drug progresses in time. From $\mathrm{s}$ to $\mathrm{u}$ : culture in the presence of $0.5 \mathrm{mM}$ alendronate for 4, 8 and 11 days, respectively; the root growth is severely hampered in these conditions; 8 - and 11-day old seedlings show an almost white colour of leaves, indicative of a very serious loss of chlorophyll.

The above results can be interpreted as a consequence of the toxic effects of BPs on the mevalonate pathway of Arabidopsis thaliana (Fig. 1). Isoprenoids, the most diverse group of natural products, are synthesized in prokaryotes and eukaryotes, animals and plants by condensation of isopentenyl pyrophosphate and dimethylallyl pyrophosphate. They play important and diverse roles in the synthesis of quinones, sterols, prenylation of proteins, photosynthetic pigments, hormones, attractants for pollinators in plants, and others. Certainly, most of the studies on the synthesis of isoprenoids were carried out in animal tissues; however, after the more recent discovery of the synthesis of isoprenoids by the mevalonate independent pathway operating in plants, new approaches on their metabolism and function have been undertaken in other biological model systems (Eisenreich et al., 2004; Lange et al., 2000; Rodriguez-Concepcion \& Boronat, 2002; Rohmer, 1999). The plastid mevalonate independent pathway involves the synthesis of 1-deoxy-D.xilulose from pyruvate and glyceraldehydes-3-phosphate. There is a cross talk between the cytosolic and plastidial pathway for the synthesis of isoprenoids in Arabidopsis thaliana (Laule et al., 2003). In relation with the postulated inhibitory role of bisphosphonates on the synthesis of isoprenoids, it could be noted that the two last compounds in that synthesis by the mevalonate independent pathway (2-C-methyl-D-erythritol 2, 4, cyclo pyrophosphate and hydroxymethybutenyl-4 pyrophosphate) both contain a terminal pyrophosphate; in addition, isopentenyl and dimethylallyl pyrophosphate, common to the two pathways, also contain a terminal pyrophosphate (Fig. 1). All these points could be raised in favour of the inhibitory effects of bisphosphonates on the synthesis of isoprenoids and hence on the development of Arabidopsis thaliana.

The mevalonate pathway is responsible, in plants, of the production of different phytohormones, among which cytokinins (Letham \& Palni, 1983). Cytokinins have been shown to reverse the effects of lovastatin, an inhibitor of 3-hydroxy-3-methylglutaryl coenzyme A reductase, the enzyme catalyzing the synthesis of mevalonate (Crowell \& Salaz 1992). Although root growth and lateral growth formation are preferentially determined by auxins, a role of cytokinins in root development has been described, coherent with their role in promoting cell division, specifically in root meristematic cells. Cytokinins, synthesized in the root cap, promote cytokinesis, vascular differentiation, root apical dominance and gravitropism (Aloni et al., 2006). Therefore, the observed effects of BPs on root growth and development may, in principle, be attributed to an inhibitory effect of BPs on cytokinins, although an indirect effect on the synthesis and/or transport of auxins cannot be excluded either. Whereas the differential effect of the various assayed BPs on root growth and development is unequivocal, additional work is necessary to understand the reasons for this differential effect and the mechanisms of the inhibition throughout the action of one or more phytohormones.

Finally, the importance of the mevalonate pathway in the biological systems can also be contemplated from an evolutionary viewpoint: isoprenoids are the oldest known biomolecules recovered from sediments, as old as 2.5 billion years (Summons et al., 2006); the mevalonate pathway is germane to archaebacteria (Lange et al., 2000) and finally, farnesyl diphosphate synthase and polypropenyl synthase activities have been reported as 
present in the hypothetical Last Universal Common Ancestor (LUCA) (Ranea et al., 2006). All the above points could be also considered as examples of the multiple relationships interconnecting all the biological cycles on earth.

\section{Conclusions}

Bisphosphonates are widely used in the treatment of osteoporosis and hence their great importance in clinical investigation. Upon their administration they bind to the bone tissues where they exert a noxious effect mainly on the mevalonate pathway of the osteoclasts. Given the universality of this pathway, present in bacteria, plants and animals, it seemed to us of interest to analyze the effect of etidronate, clodronate (non containing nitrogen or non$\mathrm{N}-\mathrm{BPs})$, pamidronate and alendronate (N-BPs) on some visible traits of the model plant Arabidopsis thaliana. The seeds were grown in a medium containing three concentrations ( $0.05 \mathrm{mM}, 0.1 \mathrm{mM}$ or $0.5 \mathrm{mM}$ ) of each bisphosphonate and the growth of primary and secondary roots and formation of chlorophyll were observed during early development of the seedlings. Each bisphosphonate showed a different pattern of influence on those parameters. In general, the inhibitory effects were, in increasing order: etidronate, pamidronate, clodronate, and alendronate. Specific effects on the evaluated parameters ranged from simple reduction in the number and length of secondary roots caused by 0.1 $\mathrm{mM}$ etidronate, only after 11 days of culture, until a drastic inhibition of seedling growth, with total loss of chlorophyll observed with $0.5 \mathrm{mM}$ alendronate already in the intermediate time point of sampling. The utility of the use of plants to analyze the action of bisphosphonates is suggested.

\section{Acknowledgments}

This work was supported by grants from the Spanish National Plan for Research, Development and Innovation (BFU 2008-00666/BMC, BFU 2009-08977 and AYA200907952). We thank Mercedes Carnota, Javier Pérez and Anabel de Diego for very helpful technical assistance.

\section{References}

Aloni, R., Aloni, E., Langhans, M. \& Ullrich, C. I. (2006). Role of cytokinin and auxin in shaping root architecture: regulating vascular differentiation, lateral root initiation, root apical dominance and root gravitropism. Ann Bot, Vol.97, No.5, (May 2006), pp. 883-893, ISSN 0305-7364

Artz, J. D., Dunford, J. E., Arrowood, M. J., Dong, A., Chruszcz, M., Kavanagh, K. L., Minor, W., Russell, R. G., Ebetino, F. H., Oppermann, U. \& Hui, R. (2008). Targeting a uniquely nonspecific prenyl synthase with bisphosphonates to combat cryptosporidiosis. Chem Biol, Vol.15, No.12, (December, 2008), pp. 1296-1306, ISSN 1074-5521

Baykov, A. A., Dubnova, E. B., Bakuleva, N. P., Evtushenko, O. A., Zhen, R. G. \& Rea, P. A. (1993). Differential sensitivity of membrane-associated pyrophosphatases to inhibition by diphosphonates and fluoride delineates two classes of enzymes. FEBS Lett, Vol.327, No.2, (July 1993), pp. 199-202, ISSN 0014-5793 
Burke, C., Klettke, K. \& Croteau, R. (2004). Heteromeric geranyl diphosphate synthase from mint: construction of a functional fusion protein and inhibition by bisphosphonate substrate analogs. Arch Biochem Biophys, Vol.422, No.1, (February 2004), pp. 52-60, ISSN 0003-9861

Cremers, S. C., Pillai, G. \& Papapoulos, S. E. (2005). Pharmacokinetics/pharmacodynamics of bisphosphonates: use for optimisation of intermittent therapy for osteoporosis. Clin Pharmacokinet, Vol.44, No.6, (June 2005), pp. 551-570, ISSN 0312-5963

Cromartie, T. H., Fisher, K. J. \& Grossman, J. N. (1999). The discovery of a novel site of action for herbicidal bisphosphonates. Pestic Biochem Phys, Vol.63, pp. 114-126.

Crowell, D. N. \& Salaz, M. S. (1992). Inhibition of Growth of Cultured Tobacco Cells at Low Concentrations of Lovastatin Is Reversed by Cytokinin. Plant Physiol, Vol.100, No.4, (December 1992), pp. 2090-2095, ISSN 0032-0889

Docampo, R. \& Moreno, S. N. (2001). Bisphosphonates as chemotherapeutic agents against trypanosomatid and apicomplexan parasites. Curr Drug Targets Infect Disord Vol.1, No.1, (May 2001), pp. 51-61, ISSN 1568-0053

Drozdowicz, Y. M., Shaw, M., Nishi, M., Striepen, B., Liwinski, H. A., Roos, D. S. \& Rea, P. A. (2003). Isolation and characterization of TgVP1, a type I vacuolar H+translocating pyrophosphatase from Toxoplasma gondii. The dynamics of its subcellular localization and the cellular effects of a diphosphonate inhibitor. J Biol Chem, Vol.278, No.2, (January 2003), pp. 1075-1085, ISSN 0021-9258

Eisenreich, W., Bacher, A., Arigoni, D. \& Rohdich, F. (2004). Biosynthesis of isoprenoids via the non-mevalonate pathway. Cell Mol Life Sci, Vol.61, No.12, (June 2004), pp. 14011426, ISSN 1420-682X

Forlani, G., Occhipinti, A., Berlicki, L., Dziedziola, G., Wieczorek, A. \& Kafarski, P. (2008). Tailoring the structure of aminobisphosphonates to target plant P5C reductase. $J$ Agric Food Chem, Vol.56, No.9, (May 2008), pp. 3193-3199, ISSN 0021-8561

Gordon-Weeks, R., Parmar, S., Davies, T. G. \& Leigh, R. A. (1999). Structural aspects of the effectiveness of bisphosphonates as competitive inhibitors of the plant vacuolar proton-pumping pyrophosphatase. Biochem J, Vol.337( Pt 3), (February 1999), pp. 373-377, ISSN 0264-6021

Günther Sillero, M. A., de Diego, A., Pérez-Zuñiga, F. J. \& Sillero, A. (2008). Synthesis of bisphosphonate derivatives of ATP by T4 DNA ligase, ubiquitin activating enzyme (E1) and other ligases. Biochem Pharmacol, Vol.75, No.10, (May 2008), pp. 1959-1965, ISSN 0006-2952

Günther Sillero, M. A., de Diego, A., Silles, E., Pérez-Zúñiga, F. \& Sillero, A. (2006). Synthesis of bisphosphonate derivatives of ATP by T4 RNA ligase. FEBS Lett, Vol.580, No.24, (October 2006), pp. 5723-5727

Günther Sillero, M. A., de Diego, A., Tavares, J. E., Silva, J. A., Pérez-Zúñiga, F. J. \& Sillero, A. (2009). Synthesis of ATP derivatives of compounds of the mevalonate pathway (isopentenyl di- and triphosphate; geranyl di- and triphosphate, farnesyl di- and triphosphate, and dimethylallyl diphosphate) catalyzed by T4 RNA ligase, T4 DNA ligase and other ligases Potential relationship with the effect of bisphosphonates on osteoclasts. Biochem Pharmacol, Vol.78, No.4, (August 2009), pp. 335-343, ISSN 18732968

Hunter, W. N. (2007). The non-mevalonate pathway of isoprenoid precursor biosynthesis. J Biol Chem, Vol.282, No.30, (July 2007), pp. 21573-21577, ISSN 0021-9258 
Kim, E. J., Zhen, R. G. \& Rea, P. A. (1994). Heterologous expression of plant vacuolar pyrophosphatase in yeast demonstrates sufficiency of the substrate-binding subunit for proton transport. Proc Natl Acad Sci U S A, Vol.91, No.13, (June 1994), pp. 6128-6132, ISSN 0027-8424

Kuo, S. Y., Chien, L. F., Hsiao, Y. Y., Van Ru, C., Yan, K. H., Liu, P. F., Mao, S. J. \& Pan, R. L. (2005). Proton pumping inorganic pyrophosphatase of endoplasmic reticulumenriched vesicles from etiolated mung bean seedlings. J Plant Physiol, Vol.162, No.2, (February 2005), pp. 129-138, ISSN 0176-1617

Lange, B. M., Rujan, T., Martin, W. \& Croteau, R. (2000). Isoprenoid biosynthesis: the evolution of two ancient and distinct pathways across genomes. Proc Natl Acad Sci U S A, Vol.97, No.24, (November 2000), pp. 13172-13177. ISSN 0027-8424

Laule, O., Furholz, A., Chang, H. S., Zhu, T., Wang, X., Heifetz, P. B., Gruissem, W. \& Lange, M. (2003). Crosstalk between cytosolic and plastidial pathways of isoprenoid biosynthesis in Arabidopsis thaliana. Proc Natl Acad Sci U S A, Vol.100, No.11, (May 2003), pp. 6866-6871, ISSN 0027-8424

Leon, A., Liu, L., Yang, Y., Hudock, M. P., Hall, P., Yin, F., Studer, D., Puan, K. J., Morita, C. T. \& Oldfield, E. (2006). Isoprenoid biosynthesis as a drug target: bisphosphonate inhibition of Escherichia coli K12 growth and synergistic effects of fosmidomycin. J Med Chem, Vol.49, No.25, (December 2006), pp. 7331-7341, ISSN 0022-2623

Letham, D. S. \& Palni, L. M. S. (1983). The biosynthesis and metaabolism of cytokinins. Annu Rev Plant Physiol, Vol. 34, pp. 163-197.

Monkkonen, H., Auriola, S., Lehenkari, P., Kellinsalmi, M., Hassinen, I. E., Vepsalainen, J. \& Monkkonen, J. (2006). A new endogenous ATP analog (ApppI) inhibits the mitochondrial adenine nucleotide translocase (ANT) and is responsible for the apoptosis induced by nitrogen-containing bisphosphonates. Br J Pharmacol, Vol.147, No.4, (Fefruary 2006), pp. 437-445, ISSN 0007-1188

Moreno, S. N. \& Li, Z. H. (2008). Anti-infectives targeting the isoprenoid pathway of Toxoplasma gondii. Expert Opin Ther Targets, Vol.12, No.3, (March 2008), pp. 253263, ISSN 1744-7631

Oberhauser, V., Gaudin, J., Fonne-Pfister, R. \& Schar, H.-P. (1998). New target enzyme(s) for bisphosphonates: Inhibition of geranylgeranyl diphosphate synthase. Pestic Biochem Phys, Vol.60, pp. 111-117.

Ranea, J. A., Sillero, A., Thornton, J. \& Orengo, C. (2006). Protein superfamilies evolution and the last universal common ancestor (LUCA). J. Mol. Evol. Vol.65, No.4, (October 2004), pp. 513-525.

Rodrígues, C. O., Scott, D. A., Bailey, B. N., De Souza, W., Benchimol, M., Moreno, B., Urbina, J. A., Oldfield, E. \& Moreno, S. N. (2000). Vacuolar proton pyrophosphatase activity and pyrophosphate (PPi) in Toxoplasma gondii as possible chemotherapeutic targets. Biochem J, Vol.349 Pt 3, (August 2000), pp. 737-745, ISSN 0264-6021.

Rodriguez-Concepcion, M. \& Boronat, A. (2002). Elucidation of the methylerythritol phosphate pathway for isoprenoid biosynthesis in bacteria and plastids. A metabolic milestone achieved through genomics. Plant Physiol, Vol.130, No.3, (November 2002), pp. 1079-1089, ISSN 0032-0889

Rogers, M. J., Brown, R. J., Hodkin, V., Blackburn, G. M., Russell, R. G. \& Watts, D. J. (1996) Bisphosphonates are incorporated into adenine nucleotides by human aminoacyl- 
tRNA synthetase enzymes. Biochem Biophys Res Commun, Vol.224, No.3, (July 1996) pp. 863-869.

Rogers, M. J., Crockett, J. C., Coxon, F. P. \& Monkkonen, J. (2010). Biochemical and molecular mechanisms of action of bisphosphonates. Bone, PubMed, in process. (November 2010), ISSN 1873-2763

Rohmer, M. (1999). The discovery of a mevalonate-independent pathway for isoprenoid biosynthesis in bacteria, algae and higher plants. Nat Prod Rep, Vol.16, No.5, (October 1999), pp. 565-574, ISSN 0265-0568

Russell, R. G. (2011). Bisphosphonates: The first 40 years. Bone, PubMed, in process. ISSN 1873-2763

Summons, R. E., Bradley, A. S., Jahnke, L. L. \& Waldbauer, J. R. (2006). Steroids, triterpenoids and molecular oxygen. Philos Trans R Soc Lond B Biol Sci, Vol.361, No.1470, (June 2006), pp. 951-968, ISSN 0962-8436

Szabo, C. M. \& Oldfield, E. (2001). An investigation of bisphosphonate inhibition of a vacuolar proton-pumping pyrophosphatase. Biochem Biophys Res Commun, Vol.287, No.2, (September 2001), pp. 468-473, ISSN 0006-291X

Wendt, K. U. \& Schulz, G. E. 1998 Isoprenoid biosynthesis: manifold chemistry catalyzed by similar enzymes. Structure, Vol.6, No.2, (February 1998), pp. 127-133, ISSN 09692126

Zhen, R. G., Baykov, A. A., Bakuleva, N. P. \& Rea, P. A. (1994) Aminomethylenediphosphonate: A Potent Type-Specific Inhibitor of Both Plant and Phototrophic Bacterial H+Pyrophosphatases. Plant Physiol, Vol.104, No.1, (January 1994), pp. 153-159, ISSN 00320889 


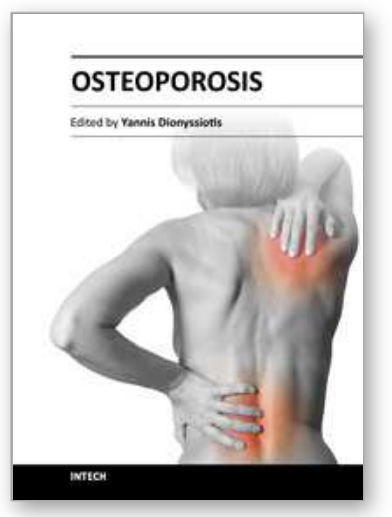

\author{
Osteoporosis \\ Edited by PhD. Yannis Dionyssiotis
}

ISBN 978-953-51-0026-3

Hard cover, 864 pages

Publisher InTech

Published online 24, February, 2012

Published in print edition February, 2012

Osteoporosis is a public health issue worldwide. During the last few years, progress has been made concerning the knowledge of the pathophysiological mechanism of the disease. Sophisticated technologies have added important information in bone mineral density measurements and, additionally, geometrical and mechanical properties of bone. New bone indices have been developed from biochemical and hormonal measurements in order to investigate bone metabolism. Although it is clear that drugs are an essential element of the therapy, beyond medication there are other interventions in the management of the disease. Prevention of osteoporosis starts in young ages and continues during aging in order to prevent fractures associated with impaired quality of life, physical decline, mortality, and high cost for the health system. A number of different specialties are holding the scientific knowledge in osteoporosis. For this reason, we have collected papers from scientific departments all over the world for this book. The book includes up-to-date information about basics of bones, epidemiological data, diagnosis and assessment of osteoporosis, secondary osteoporosis, pediatric issues, prevention and treatment strategies, and research papers from osteoporotic fields.

\title{
How to reference
}

In order to correctly reference this scholarly work, feel free to copy and paste the following:

Ana I. Manzano, F. Javier Medina, Francisco J. Pérez-Zuñiga, Maria A. Günther Sillero and Antonio Sillero (2012). Effect of Bisphosphonates on Root Growth and on Chlorophyll Formation in Arabidopsis thaliana Seedlings, Osteoporosis, PhD. Yannis Dionyssiotis (Ed.), ISBN: 978-953-51-0026-3, InTech, Available from: http://www.intechopen.com/books/osteoporosis/effect-of-bisphosphonates-on-root-growth-and-on-chlorophyllformation-in-arabidopsis-thaliana-seedli

\section{INTECH}

open science | open minds

\author{
InTech Europe \\ University Campus STeP Ri \\ Slavka Krautzeka 83/A \\ 51000 Rijeka, Croatia \\ Phone: +385 (51) 770447 \\ Fax: +385 (51) 686166 \\ www.intechopen.com
}

\author{
InTech China \\ Unit 405, Office Block, Hotel Equatorial Shanghai \\ No.65, Yan An Road (West), Shanghai, 200040, China \\ 中国上海市延安西路65号上海国际贵都大饭店办公楼405单元 \\ Phone: +86-21-62489820 \\ Fax: $+86-21-62489821$
}

